\title{
A Microstructural Study on the Observed Differences in Charpy Impact Behavior Between Hot Isostatically Pressed and Forged 304L and 316L Austenitic Stainless Steel
}

\author{
ADAM J. COOPER, NORMAN I. COOPER, ANDREW BELL, JEAN DHERS, and \\ ANDREW H. SHERRY
}

\begin{abstract}
With near-net shape technology becoming a more desirable route toward component manufacture due to its ability to reduce machining time and associated costs, it is important to demonstrate that components fabricated via Hot Isostatic Pressing (HIP) are able to perform to similar standards as those set by equivalent forged materials. This paper describes the results of a series of Charpy tests from HIP'd and forged 304L and 316L austenitic stainless steel, and assesses the differences in toughness values observed. The pre-test and post-test microstructures were examined to develop an understanding of the underlying reasons for the differences observed. The as-received microstructure of HIP'd material was found to contain micro-pores, which was not observed in the forged material. In tested specimens, martensite was detectable within close proximity to the fracture surface of Charpy specimens tested at $77 \mathrm{~K}\left(-196{ }^{\circ} \mathrm{C}\right)$, and not detected in locations remote from the fracture surface, nor was martensite observed in specimens tested at ambient temperatures. The results suggest that the observed changes in the Charpy toughness are most likely to arise due to differences in as-received microstructures of HIP'd $v s$ forged stainless steel.
\end{abstract}

DOI: $10.1007 / \mathrm{s} 11661-015-3140-9$

(C) The Minerals, Metals \& Materials Society and ASM International 2015

\section{INTRODUCTION}

Hot Isostatic Pressing, or 'HIPing', is an increasingly attractive approach for manufacture, by which high quality metal powder of required chemistry is poured into a form, and subjected to elevated temperatures [typically $1223 \mathrm{~K}$ to $1433 \mathrm{~K} \quad\left(950{ }^{\circ} \mathrm{C}\right.$ to $\left.\left.1160{ }^{\circ} \mathrm{C}\right)\right]^{[1]}$ and isostatically controlled pressures $(100 \mathrm{MPa})^{[1]}$ under an inert atmosphere. ${ }^{[2]}$ The merits of HIP'd steel over conventional steel are well documented $^{[1,3-7]}$; HIP'd materials typically display an increased yield strength, ultimate tensile strength, and enhanced ductility over their forged counterparts. ${ }^{[4]}$ The HIP'd materials typically exhibit a finer grain structure than conventionally forged materials. ${ }^{[8]}$ The application of high pressure and an inert gas atmosphere allows the sintering of internal voids ${ }^{[9]}$ and significantly, the isostatically applied pressure ensures the grain microstructure is isotropic in geometry and in

ADAM J. COOPER, Postdoctoral Research Associate, is with the School of Materials, University of Manchester, Oxford Road, Manchester, M13 9PL, UK Contact e-mail: adam.cooper@manchester. ac.uk NORMAN I. COOPER, Head of Materials Technology, and ANDREW BELL, Principle Metallurgist, are with BAE Systems, Bridge Road, Barrow-in-Furness, LA14 1AF, UK. ANDREW H. SHERRY, Chief Scientist, is with the National Nuclear Laboratory, Chadwick House, Birchwood Park, Warrington, WA3 6AE, UK. JEAN DHERS, Manager of Areva Research and Development, is with the AREVA European R\&D, Areva, France.

Manuscript submitted May 27, 2015.

Article published online September 3, 2015 properties, exhibiting no texture or anisotropy as observed in some forgings and in rolled plates. This fine and isotropic grain structure is deemed the fundamental reasoning behind the observed enhanced mechanical properties associated with HIP'd materials. ${ }^{[3]}$ Furthermore, the finer grain structure induces a greater concentration of grain boundaries per unit volume, at which any inclusions and/or impurities are able to reside. ${ }^{[4]}$

A significant advantage of HIPping over conventional manufacture routes, at least from an engineering perspective, lies in the potential for near-net shape manufacture $^{[5,8,10]}$ where it is possible to manufacture components with geometries of greater complexity than those achievable from forging. The design freedom is ultimately governed and limited by the ability to produce a capsule from which the HIPped component is molded. In addition, the finer grain size of the HIP'd material enhances non-destructive analysis, such as ultrasonic 'time of flight'.

Finally, HIP'd NNS components can be manufactured using as much as 80 to 90 pct of the original starting material, in contrast to a comparatively poor throughput of 10 to $30 \mathrm{pct}$ from forged materials, where a large proportion of material is unrecovered during machining. ${ }^{[9]}$

The efficiency of material use and the potential to reduce the number of welds by HIP has the potential to both drive down manufacturing costs and improve service life for engineering components such as those 
Table I. Elemental Compositions of Tested Materials

\begin{tabular}{|c|c|c|c|c|c|c|c|c|}
\hline & $\mathrm{Cr}$ & $\mathrm{Ni}$ & Mo & $\mathrm{Mn}$ & $\mathrm{Si}$ & $\mathrm{C}$ & $\mathrm{O}(\mathrm{Ppm})$ & $\mathrm{N}(\mathrm{Ppm})$ \\
\hline \multicolumn{9}{|l|}{$304 \mathrm{~L}$} \\
\hline Spec. (wt pct) & 18.5 to 20.00 & 9.00 to 10.00 & - & $<2.00$ & $<1.00$ & $<0.035$ & 200 & - \\
\hline Forged & 19.402 & 9.648 & 0.345 & 1.654 & 0.573 & 0.027 & 15 & 817 \\
\hline Powder (wt pct) & 19.2 & 9.44 & - & 1.37 & 0.74 & 0.022 & 110 & - \\
\hline HIP (wt pct) & 19.5 & 9.45 & 0.01 & 1.33 & 0.72 & 0.022 & 120 & 840 \\
\hline \multicolumn{9}{|l|}{$316 \mathrm{~L}$} \\
\hline Spec. (wt pct) & 17.00 to 18.00 & 11.50 to 12.50 & 2.25 to 2.75 & $<2.00$ & $<1.00$ & $<0.035$ & - & - \\
\hline Powder (wt pct) & 17.1 & 11.6 & 2.33 & 1.29 & 0.61 & 0.013 & 125 & - \\
\hline HIP (wt pct) & 17.2 & 11.85 & 2.30 & 1.37 & 0.60 & 0.016 & 120 & 370 \\
\hline
\end{tabular}

used in the nuclear sector. However, the introduction of new processes must be accompanied by a materials dataset that demonstrates adequate properties, as well as new understanding that shows any differences from conventionally forged materials are fully characterized from a mechanistic point of view.

This study was developed due to the observed differences in impact toughness between equivalent forged and HIP'd stainless steel when performing routine Charpy tests. HIP'd specimens exhibited consistently lower impact toughness than forged specimens over a wide range of temperatures; temperatures at which a plasticity-induced transformation of ductile austenite to brittle martensite can occur. The austenite $(\gamma)$ to martensite $\left(\alpha^{\prime}\right)$ transition is a well-known diffusionless phase transformation, ${ }^{[1-14]}$ in which the atoms within the $\gamma$ face centered cubic (FCC) matrix are realigned as new crystal lattices. This realignment not only results in a different orientation but also produces a different crystal structure, termed martensite, and can have either a body centered tetragonal (BCT) phase or a body centered cubic (BCC) phase depending on the carbon content of the steel. ${ }^{[15,16]}$ The BCT structure prevails in carbon steels, where there is sufficient carbon to cause tetragonal distortion of the BCC lattice. A martensitic transformation of the FCC matrix can operate via two mechanisms; the first is via quenching of the $\gamma$ matrix to temperatures below the martensitic start temperature, $M_{\mathrm{S}}$, which is related to the carbon content of the material, during which the metastable $\gamma$ phase is converted to smaller crystalline units, of BCT phase, via diffusionless transformation. ${ }^{[13,17]}$

The second mechanism by which martensitic transformation can occur, is strain-induced, as demonstrated in transformation induced plasticity (TRIP) steels, where the retained austenite is transformed into martensite during plastic deformation of the austenite matrix. ${ }^{[13]}$ Because the transformation is strain-assisted, the energy required for appreciable martensitic transformation is reduced, and therefore the temperature at which martensitic transformation occurs is no longer restricted to temperatures below the material's $M_{\mathrm{s}}$ temperature. $^{[18,19]}$

Regardless of the mechanism, the effects of martensitic transformation on the mechanical properties of a material are the same: introduction of a ferromagnetic and much more brittle phase within the austenite matrix lowers the overall fracture toughness and ductility of the component, and produces regions of enhanced hardness. The greater the degree of martensitic transformation, the more susceptible the component is to brittle failure. This is of a concern in demanding environments where high toughness and high ductility are essential and likely to be the required attributes for which the austenitic steel was originally selected.

\section{EXPERIMENTAL}

The present study is based on industrially supplied HIP'd 304L and 316L material from AREVA, and industrially supplied 304L stainless steel from Creusot Forge et Creusot Mécanique, AREVA, France.

Table I shows the elemental compositions of the forged and HIP materials, as well as the elemental composition of the respective powders from which the HIP materials were manufactured. All materials are within specification. The HIP materials display higher oxygen content by nearly one order of magnitude.

For HIP304L, 304L powder was heated from ambient temperature to $1423 \mathrm{~K}\left(1150{ }^{\circ} \mathrm{C}\right)$ at a rate of $360 \mathrm{~K} \mathrm{~h}^{-1}$ $\left(360{ }^{\circ} \mathrm{C} \mathrm{h}^{-1}\right)$, and held at $1423 \mathrm{~K}\left(1150{ }^{\circ} \mathrm{C}\right)$ and $104 \mathrm{Mpa}$ for a period of 180 minutes. Cooling was performed at a rate of $240 \mathrm{~K} \mathrm{~h}^{-1}\left(240{ }^{\circ} \mathrm{C} \mathrm{h}^{-1}\right)$. PostHIP heat treatment of HIP304L was performed by heating from room temperature to $1343 \mathrm{~K}\left(1070{ }^{\circ} \mathrm{C}\right)$ at $360 \mathrm{~K} \mathrm{~h}^{-1}\left(360{ }^{\circ} \mathrm{C} \mathrm{h}^{-1}\right)$, held for 280 minutes, and water quenched. For HIP316L, 316L powder was heated from ambient temperature to $1423 \mathrm{~K}\left(1150{ }^{\circ} \mathrm{C}\right)$ at a rate of $220 \mathrm{~K} \mathrm{~h}^{-1}\left(220^{\circ} \mathrm{C} \mathrm{h}^{-1}\right)$, and held at $1423 \mathrm{~K}$ $\left(1150{ }^{\circ} \mathrm{C}\right.$ ) and $105 \mathrm{MPa}$ for a period of 210 minutes. Cooling was performed at a rate of $240 \mathrm{~K} \mathrm{~h}^{-1}$ $\left(240{ }^{\circ} \mathrm{C} \mathrm{h}^{-1}\right)$. Post-HIP heat treatment of HIP304L was performed by heating from room temperature to $1343 \mathrm{~K}\left(1070{ }^{\circ} \mathrm{C}\right)$ at $360 \mathrm{~K} \mathrm{~h}^{-1}\left(360{ }^{\circ} \mathrm{C} \mathrm{h}^{-1}\right)$, held for 280 minutes, and water quenched.

Forged $304 \mathrm{~L}$ pipe was subjected to similar heat treatment as the HIP materials [1343 K $\left(1070{ }^{\circ} \mathrm{C}\right)$, for ca. 250 minutes] and water quenched.

Charpy V-notch specimens were machined in accordance with ASTM A370 recommended $^{[20]}$ dimensions $(10 \times 10 \times 55 \mathrm{~mm})$, and the $\mathrm{V}$-notch was machined by electrical discharge machining (EDM). Forged 304L Charpy specimens were extracted from a pipe section 
and machined with CR orientation, where $C=$ circumferential direction and $R=$ radial direction. HIP Charpy specimens were extracted from square blocks and machined with LT orientation, where $L=$ longitudinal direction and $T=$ transverse direction, though the isotopic nature of the HIP grain structure means that the orientation of HIP specimens is not important. Charpy impact testing was performed using an instrumented Charpy testing rig (impact velocity $=5.23 \mathrm{~m} \mathrm{~s}^{-1}$ ) Samples were cooled to $173 \mathrm{~K}$ $\left(-100{ }^{\circ} \mathrm{C}\right)$ using a liquid nitrogen controlled fridge, and cooled to $77 \mathrm{~K}\left(-196^{\circ} \mathrm{C}\right)$ by submerging in liquid nitrogen for $c a$. 20 minutes prior to testing. Samples were heated to $473 \mathrm{~K}$ and $573 \mathrm{~K}\left(200{ }^{\circ} \mathrm{C}\right.$ and $\left.300{ }^{\circ} \mathrm{C}\right)$ by placing in an oven for 30 minutes.

Specimens prepared for metallurgical analysis were sectioned lengthways at the mid-section and perpendicular to the notch root, mounted, ground, and polished in accordance with the recommended procedures in ASTM Practice E3-01. ${ }^{[21]}$ Specimens were electro-etched in $10 \mathrm{wt}$ pct oxalic acid solution, at a voltage of $+3 \mathrm{~V}$ for 30 seconds, in order to enhance grain-boundary contrast. In order to protect the fracture surface edge when grinding/polishing samples for metallographic inspection close to the fracture surface, specimens were either electroplated with nickel or mounted in an edge-retentive and electrically conductive epoxy resin.

Electron microscopy was performed using an FEI Quanta 650 ESEM and an FEI Sirion SEM, both equipped with field emission guns and electron back-scattered diffraction (EBSD) detectors, and a Hitachi S-3700 scanning electron microscope equipped with Oxford Instruments INCA X-ACT energy dispersive spectroscopy for semi-quantitative chemical analysis. The SEM was performed under vacuum using an $8 \mathrm{kV}$ accelerating voltage and a spot size of $4.0 \mathrm{~nm}$, at a working distance (WD) of approximately $15 \mathrm{~mm}$. Fractography was undertaken on selected failed specimens, using SEM and optical imaging.

Ferromagnetic measurements were recorded using a Fischer Ferritescope MP3. The reported percentage Ferrite values are the average of six readings. Due to the size of the probe $(c a .2 \mathrm{~mm})$ in relation to the size of the sample the locations indicated in the table of results are approximate.

Automated microhardness mapping of metallographic sections was carried out using a PC controlled Zwick-Roell ZHV30 hardness tester using ZH $\mu$ HD microhardness software. The Charpy samples were sectioned longitudinally down the central axis and mounted, ground, and polished to a $1 \mu \mathrm{m}$ finish, in accordance with the recommended procedures in ASTM Practice E3-01, ${ }^{[21]}$ prior to testing. All testing was performed using a Vickers indenter, a $0.2 \mathrm{~kg}$ load and a spacing of $150 \mu \mathrm{m}$ between indents. Maps were constructed from between 3000 and 9000 hardness indents each. Indentation was either performed after the ferromagnetic measurements, or specimens were sufficiently re-polished prior to microhardness indentation to avoid any impact of indentation on the acquired ferrite readings.

\section{RESULTS}

\section{A. Microstructural Analysis of As-Received Materials}

Figure 1 shows the as-received microstructure of (a) HIP304L, (b) HIP316L, and (c) F304L materials. The mean grain size of the HIP304L material was measured using the linear intercept method, as per ASTM E112-96, ${ }^{[2]}$ and was determined to be $27 \mu \mathrm{m}$, with a standard deviation of 9. A similar average grain size was determined for the HIP316L material: $29 \mu \mathrm{m}$, with a standard deviation of 9, also. The F304L material had a mean grain size of $94 \mu \mathrm{m}$, with a standard deviation of 14. The SEM micrographs show the presence of micron scale pores in the HIP materials, which was observable at greater than $\times 1000$ magnification, and was not observed in chemically equivalent forged material. These pores showed no preference to manifest at specific microstructural features such as grain boundaries, appearing also within grains. The micro-pores present in the HIP materials prevented clear grain identification via standard optical microscopy and oxalic acid etching (etching revealed further micro-pores, which made identification of grain boundaries challenging) hence the use of SEM for microstructural assessment of the HIP materials.

Figures 2(a) and (b) show the micro-pores in HIP304L and HIP316L, respectively, after slight etching in oxalic acid. However, micro-pores were visible, albeit to a smaller extent, even after polishing to a $1 / 4 \mu \mathrm{m}$ diamond-suspension finish, indicating that chemical etching is not solely responsible for their initial presence, though etching did enhance the degree of visible micro-pores.

H304L pore size analysis (total of 1400 pores from $10 \mathrm{SEM}$ images) revealed an average pore size of $0.23 \mu \mathrm{m}^{2}$, with a standard deviation of 0.43 . H316L pore size analysis revealed an average pore size of $0.26 \mu \mathrm{m}^{2}$, with a standard deviation of 0.48 . These lateral 2D pore sizes should not be confused with 3D pore volumes, since metallographic sectioning does not guarantee the intersection of pores at their equators. It can therefore be assumed that the average volume of pores is slightly greater than the lateral dimensions suggest, since intersection of pores at any point other than the pore equator will result in $2 \mathrm{D}$ pores with lateral diameters smaller than the original pore diameters. No micro-pores were visible in chemically equivalent forged material, after any of the surface preparation stages.

The SEM image in Figure 3 shows the presence of both the previously shown micro-pores and also clear non-metallic inclusions, after polishing to a $1 / 4 \mu \mathrm{m}$ diamond-suspension finish; the chemical analyses of which are tabulated and indicate they are oxide-based. Although the inclusions analyzed are comparatively large with respect to the micro-pores, there is a pore 

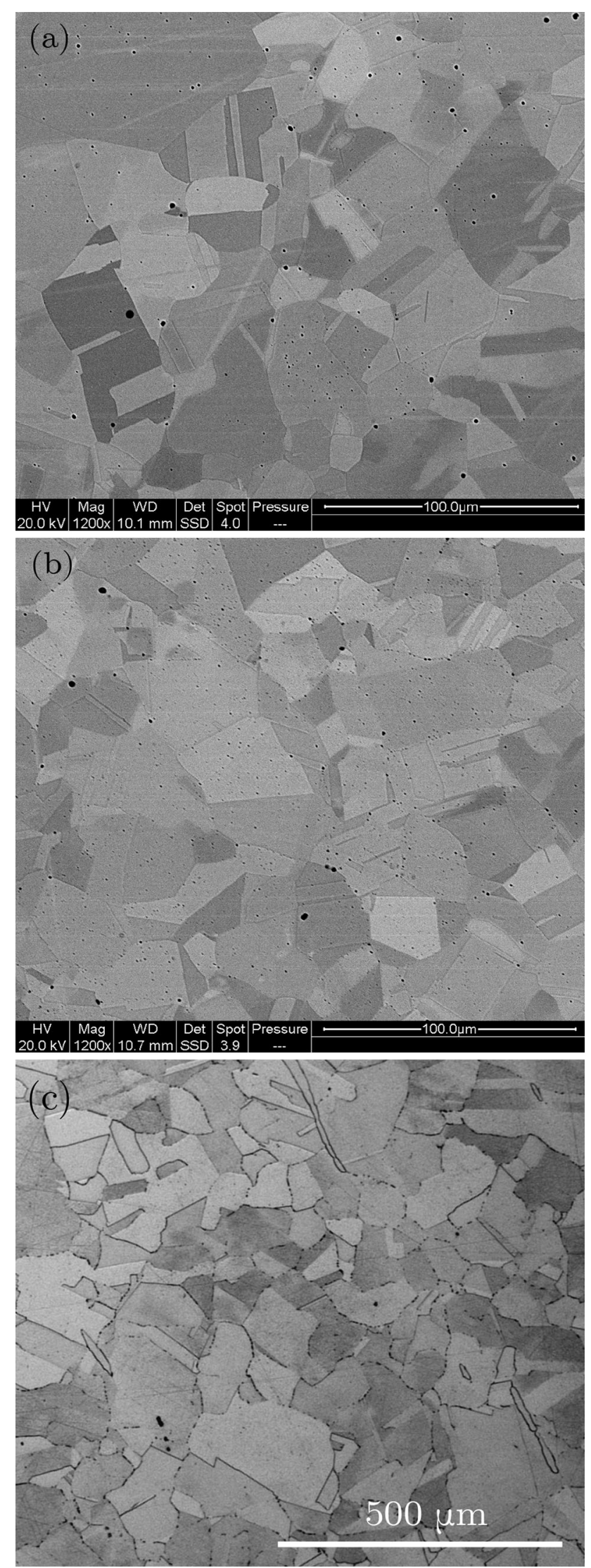

Fig. 1-SEM micrographs showing microstructure of as-received $(a)$ HIP 304L, (b) HIP 316L, and (c) F304L, after polishing and etching with oxalic acid.
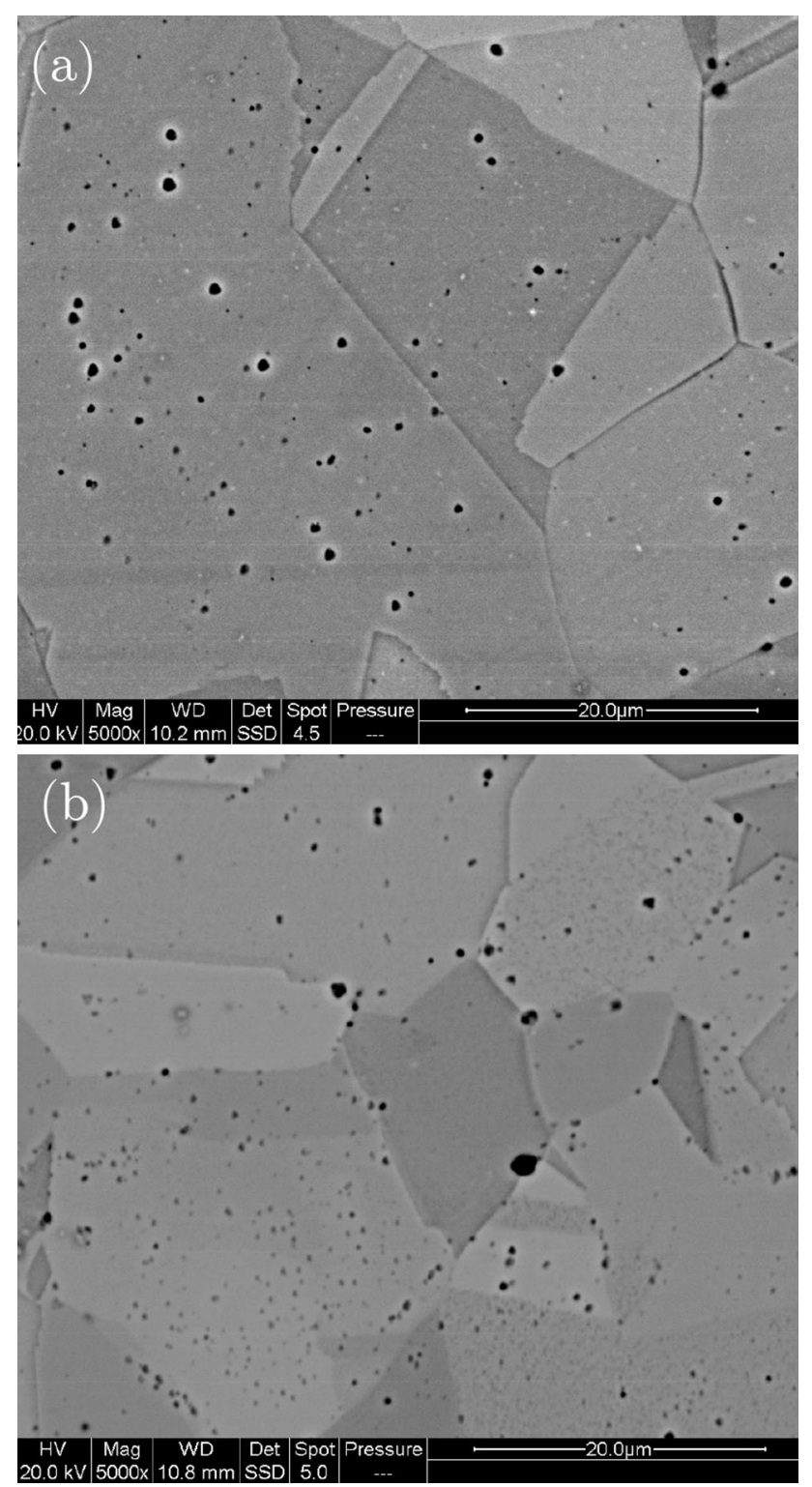

Fig. 2-SEM images showing the effects of etching on visible holes- (a) HIP304L after etching, (b) HIP316L after etching in oxalic acid solution.

close to S2 that is charging, suggesting that it contains non-metallic material.

\section{B. Charpy Impact Toughness Data}

Charpy impact values for all materials are presented in Figure 4. In all cases, the impact toughness reduces with decreasing temperature, when $T \leq 293 \mathrm{~K}\left(20^{\circ} \mathrm{C}\right)$. The gradient of this variation for the HIP and forged materials are within $c a$. 10 pct. Seven data points, or Charpy tests, used to construct each " $\mathrm{m}_{1}$ " linear regression fit. For the " $\mathrm{m}_{2}$ " gradients, 4 tests were used for each of the HIP trends, and 6 tests used for the F304L trend. In the case of forged 304L, this relationship holds to ca. ambient temperature, where it then falls by almost $100 \mathrm{~J}$ at $573 \mathrm{~K}\left(300{ }^{\circ} \mathrm{C}\right)$. In the case of HIP 


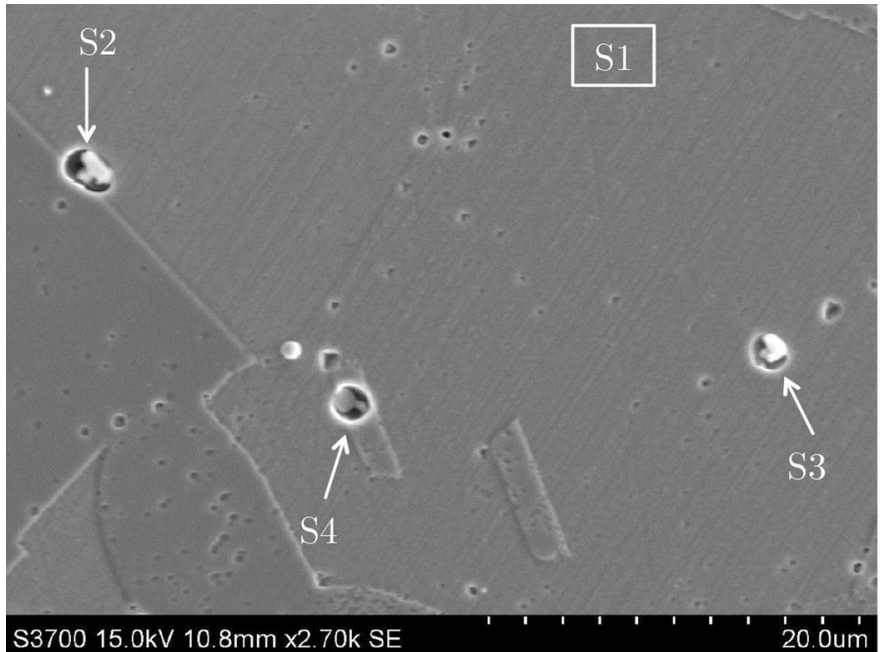

\begin{tabular}{|c|c|c|c|c|}
\hline$\%$ & $\mathrm{~S} 1$ & $\mathrm{~S} 2$ & $\mathrm{~S} 3$ & $\mathrm{~S} 4$ \\
\hline $\mathrm{Fe}$ & 64.8 & 6.2 & 17.5 & 22.9 \\
$\mathrm{Cr}$ & 17.7 & 6.4 & 11.9 & 9.7 \\
$\mathrm{Ni}$ & 12.5 & 0.7 & 2.8 & 3.2 \\
$\mathrm{Mo}$ & 2.5 & 0.7 & 1.5 & 0.7 \\
$\mathrm{Mn}$ & 1.8 & 32.6 & 27.2 & 29.8 \\
$\mathrm{Si}$ & 0.8 & 18.7 & 13.1 & 14.0 \\
$\mathrm{O}$ & - & 34.5 & 25.7 & 19.3 \\
$\mathrm{Ti}$ & - & 0.2 & 0.4 & - \\
$\mathrm{Al}$ & - & - & 0.1 & - \\
$\mathrm{Ca}$ & - & - & - & 0.3 \\
\hline
\end{tabular}

Fig. 3-SEM image showing both the presence of holes and non-metallic oxide-inclusions, the chemical analyses of which are tabulated.

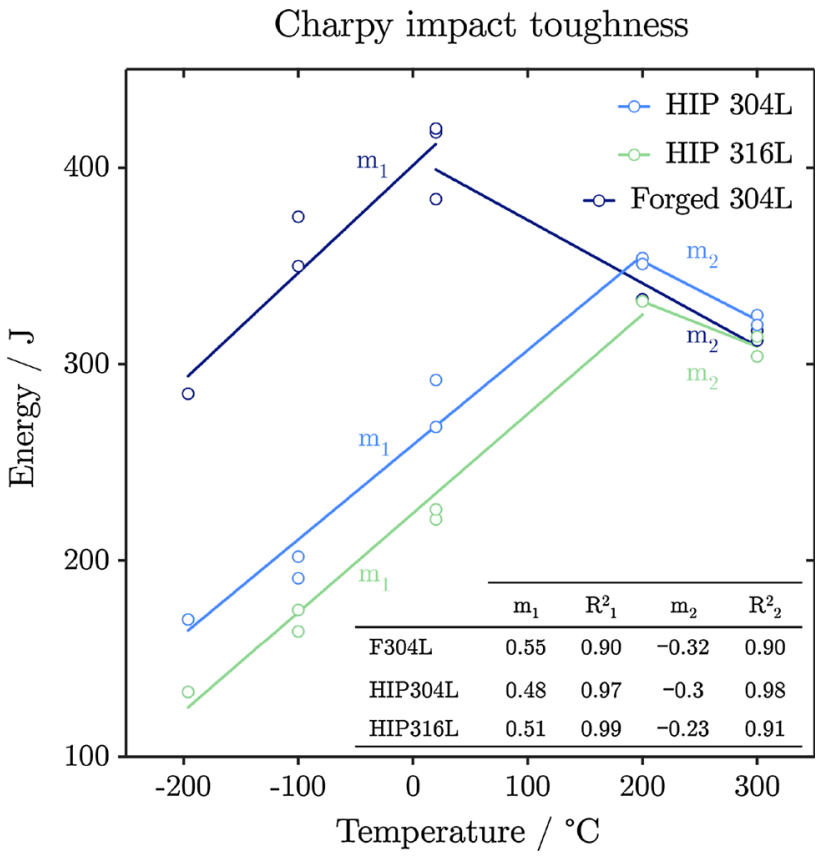

Fig. 4 - Charpy impact toughness data for HIP304L, HIP316L and chemically equivalent forged $304 \mathrm{~L}$ material, over a temperature range $573 \mathrm{~K}$ to $77 \mathrm{~K}\left(300{ }^{\circ} \mathrm{C}\right.$ to $\left.-196{ }^{\circ} \mathrm{C}\right)$.

specimens, this relationship holds to a temperature of $473 \mathrm{~K}\left(200{ }^{\circ} \mathrm{C}\right)$ before depreciating slightly.

There is a significant difference between the toughness associated with the HIP304L specimens $c f$. forged specimens $304 \mathrm{~L}$ over the entire temperature range; HIP304L exhibits a Charpy impact toughness almost $200 \mathrm{~J}$ lower than that of F304L. None of the forged 304L Charpy specimens failed completely, and HIP specimens did not fail completely when tested at and above $473 \mathrm{~K}\left(200{ }^{\circ} \mathrm{C}\right)$. For the majority of the tested specimens therefore,

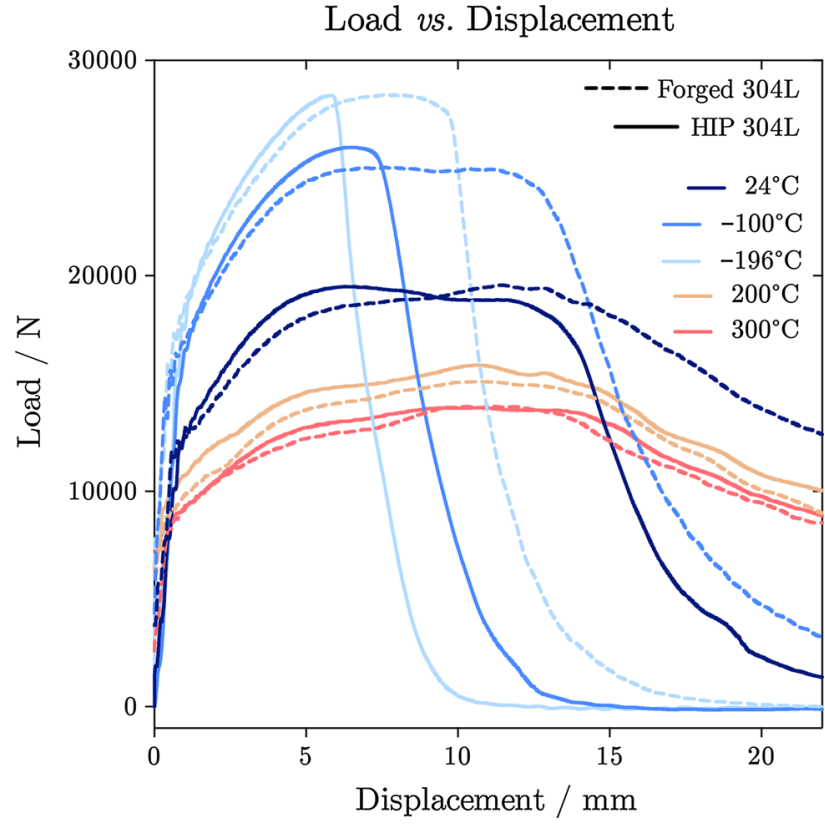

Fig. 5-Instrumented charpy impact data showing force vs. displacement for HIP (solid lines) and Forged (dashed lines) variations of 304L.

the Charpy impact energy is a measure of the energy consumed in the combination of the plastic deformation and fracture necessary for the specimen to pass through the anvil, and not simply the energy required to break the specimen into two pieces.

Figure 5 shows a comparison of the load vs displacement curves for $\mathrm{F} 304 \mathrm{~L}$ (dashed lines) and HIP304L (solid lines), at various temperatures. The amount of absorbed energy (area under the curve) for both materials is of similar magnitude at elevated temperatures $\left[T \geq 473 \mathrm{~K} \quad\left(200{ }^{\circ} \mathrm{C}\right)\right]$, but there is 


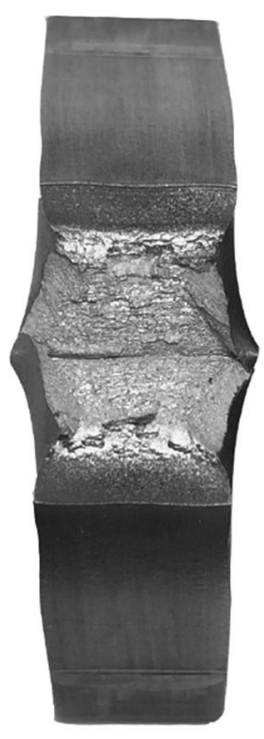

(a)

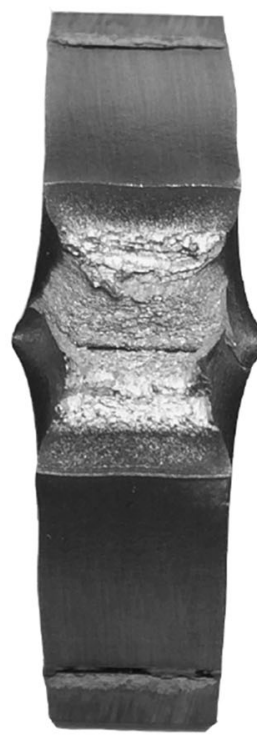

(b)

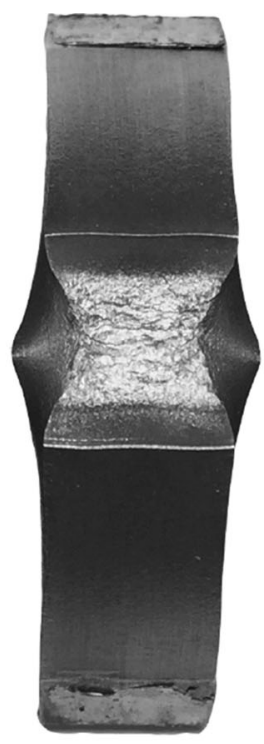

(c)

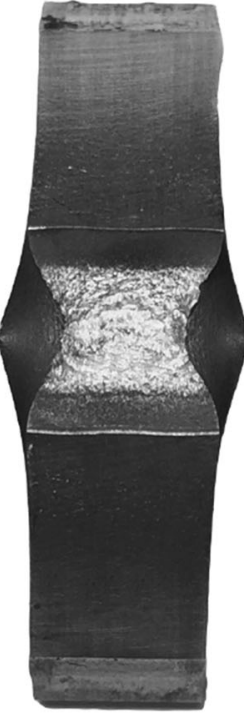

(d)

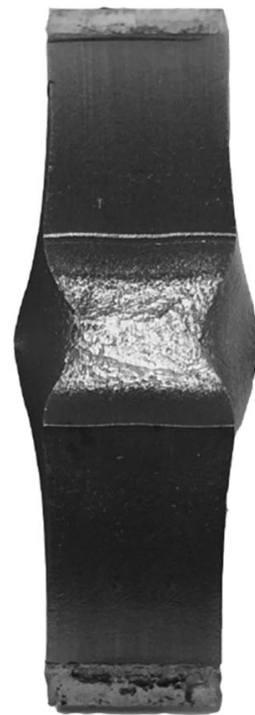

(e)

Fig. 6-Photographs showing failed F304L Charpy specimens tested at $($ a $) 77 \mathrm{~K}\left(-196{ }^{\circ} \mathrm{C}\right),(b) 173 \mathrm{~K}\left(-100{ }^{\circ} \mathrm{C}\right),(c) 293 \mathrm{~K}\left(20{ }^{\circ} \mathrm{C}\right),($ d $) 473 \mathrm{~K}$ $\left(200{ }^{\circ} \mathrm{C}\right)$, and $(e) 573 \mathrm{~K}\left(300^{\circ} \mathrm{C}\right)$.

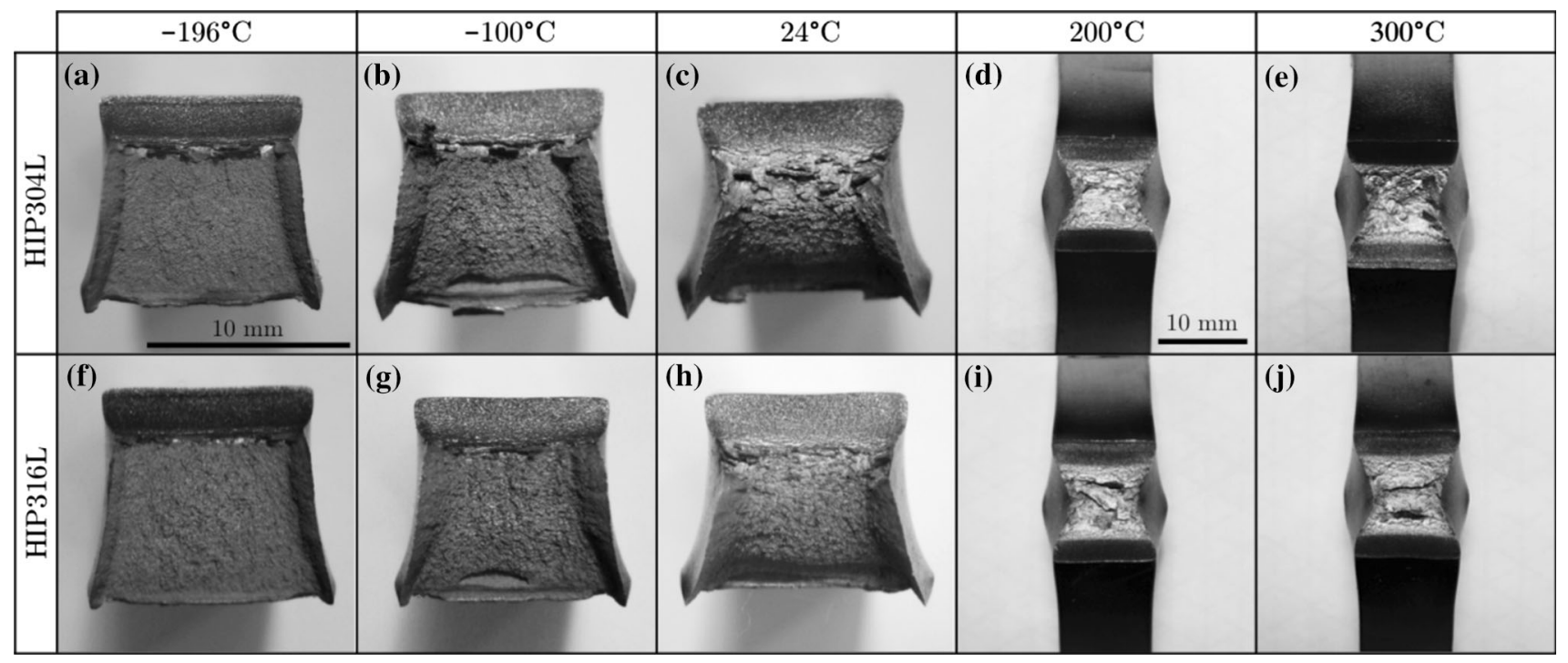

Fig. 7-Photographs showing fracture surfaces of failed HIP304L (top row) Charpy specimens tested at $(a) 77 \mathrm{~K}\left(-196{ }^{\circ} \mathrm{C}\right)$, $(b) 173 \mathrm{~K}$ $\left(-100{ }^{\circ} \mathrm{C}\right),(c) 293 \mathrm{~K}\left(20^{\circ} \mathrm{C}\right),(d) 473 \mathrm{~K}\left(200{ }^{\circ} \mathrm{C}\right)$, and $(e) 573 \mathrm{~K}\left(300{ }^{\circ} \mathrm{C}\right)$, and failed HIP316L (bottom row) Charpy specimens tested at $(f) 77 \mathrm{~K}$ $\left(-196{ }^{\circ} \mathrm{C}\right),(\mathrm{g}) 173 \mathrm{~K}\left(-100{ }^{\circ} \mathrm{C}\right),(h) 293 \mathrm{~K}\left(20^{\circ} \mathrm{C}\right),(i) 473 \mathrm{~K}\left(200{ }^{\circ} \mathrm{C}\right)$, and $(j) 573 \mathrm{~K}\left(300{ }^{\circ} \mathrm{C}\right)$, exhibiting significant embrittlement in both materials when tested at depreciated temperatures. Specimens tested at $473 \mathrm{~K}$ and $573 \mathrm{~K}\left(200{ }^{\circ} \mathrm{C}\right.$ and $\left.300{ }^{\circ} \mathrm{C}\right)$ did not fail into two separate fragments due to excessive plasticity.

significant difference between the absorbed energy for each material at lower temperatures $[T<473 \mathrm{~K}$ $\left.\left(200{ }^{\circ} \mathrm{C}\right)\right]$. There is also a difference in ductility between the two materials at cryogenic temperatures, where the HIP304L exhibits less ductility to the comparatively large degree of plastic deformation exhibited by F304L. The onset and degree of nonlinearity at each test temperature is comparable between HIP and forged 304L materials, indicating that the reduction in impact toughness observed for HIP materials at a given temperature is a function of the reduced ductility.

\section{Fractographic Assessment}

Figure 6 shows the failed F304L specimens, highlighting that complete fracture did not occur regardless of test temperature, instead producing single fragments with varying degrees of plastic deformation and fracture; the magnitude of crack opening is related to the decreasing test temperature, with greater crack opening and less plastic deformation being observed in specimens tested at lower temperatures.

In contrast, Figure 7 shows optical images of failed HIP304L (Figures 7(a) through (e)) and 316L 
(Figures 7(f) through (j)) fracture surfaces, where (a, f), $(\mathrm{b}, \mathrm{g}),(\mathrm{c}, \mathrm{h}),(\mathrm{d}, \mathrm{i})$, and $(\mathrm{e}, \mathrm{j})$ were tested at $73 \mathrm{~K}, 173 \mathrm{~K}$, $293 \mathrm{~K}, 473 \mathrm{~K}$, and $573 \mathrm{~K}\left(-196{ }^{\circ} \mathrm{C},-100{ }^{\circ} \mathrm{C}, 20{ }^{\circ} \mathrm{C}\right.$, $200{ }^{\circ} \mathrm{C}$, and $300{ }^{\circ} \mathrm{C}$ ), respectively. Only HIP specimens failed completely, when tested at ambient temperatures and below.

Measurements of lateral deformation in all tested specimens are summarized in Figure 8(a) which shows the maximum level of lateral contraction below the notch as a function of test temperature, and Figure 8(b) which shows lateral expansion at the back face of the specimens. The lateral contraction data indicate the broad similarity in deformation behavior of HIP304L and HIP316L specimens tested below ambient temperature. The F304L specimens exhibited greater deformation in this temperature range, effectively shifting the ductility $v s$ temperature curve for the HIP'd specimens by $c a .373 \mathrm{~K}\left(100{ }^{\circ} \mathrm{C}\right)$ to the left. At temperatures between $473 \mathrm{~K}$ and $573 \mathrm{~K}\left(200{ }^{\circ} \mathrm{C}\right.$ and $\left.300^{\circ} \mathrm{C}\right)$, all materials exhibited similar levels of lateral contraction. The lateral expansion data exhibit a slightly different trend, indicating a higher ductility in forged compared with HIP'd specimens over the full temperature range.

Figures 6 and 7, along with the Charpy impact data in Figures 4 and 5, and the lateral contraction measurements in Figure 8(a), indicate that HIP304L and F304L fail in similar fashions when tested at and above $473 \mathrm{~K}$ $\left(200{ }^{\circ} \mathrm{C}\right)$, generating similar force $v s$. displacement data, lateral contraction deformation, and comparable Charpy impact energies. The differences in fracture and recorded Charpy energies between chemically equivalent HIP'd and forged 304L stainless steel, only become significant at ambient temperatures and below, where HIP specimens fracture completely into two fragments.

Figure 9 shows fractographic assessment of failed Charpy specimens: F304L (a, c) and HIP304L (b, d). For SEM analysis of specimens that failed to fracture as two separate fragments, specimens were forced apart manually but only the Charpy-generated fracture surface was studied.

The SEM images in Figures 9(a) and (b) reveal subtle macro-scale differences in fracture morphology between F304L and H304L; though the fracture remains ductile in nature in both cases, indicated by the extent of ductile dimpling, regions of ductile dimpling in HIP304L appear to be segmented into grain-sized and grain-shaped regions, exhibiting discontinuity between areas and an almost intergranular-like fracture appearance. Examples of this segmentation have been magnified in the two inset fractographs in Figure 9(b). These segmented features were representative of the entire Charpy-generated fracture surface, and there was little difference in macro-scale fractographic features between specimens tested at $293 \mathrm{~K}$ and $77 \mathrm{~K} \quad\left(20{ }^{\circ} \mathrm{C}\right.$ and $\left.-196^{\circ} \mathrm{C}\right)$. This could be attributed to the finer grain size of the HIP material $c f$. the forged material. Further analysis of both HIP and forged materials at enhanced magnification, (c) and (d), only ever revealed extensive ductile dimpling, and no indication of brittle failure was observable.
Lateral contraction $v s$. temperature

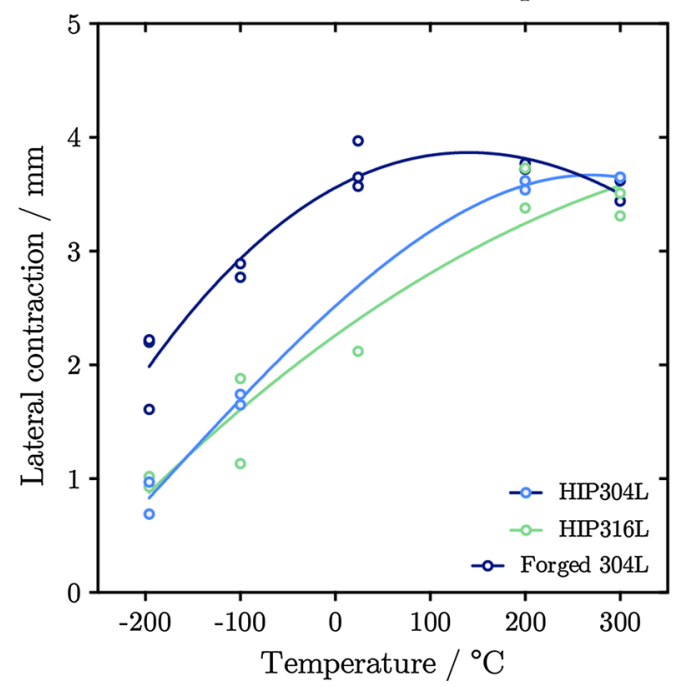

(a)

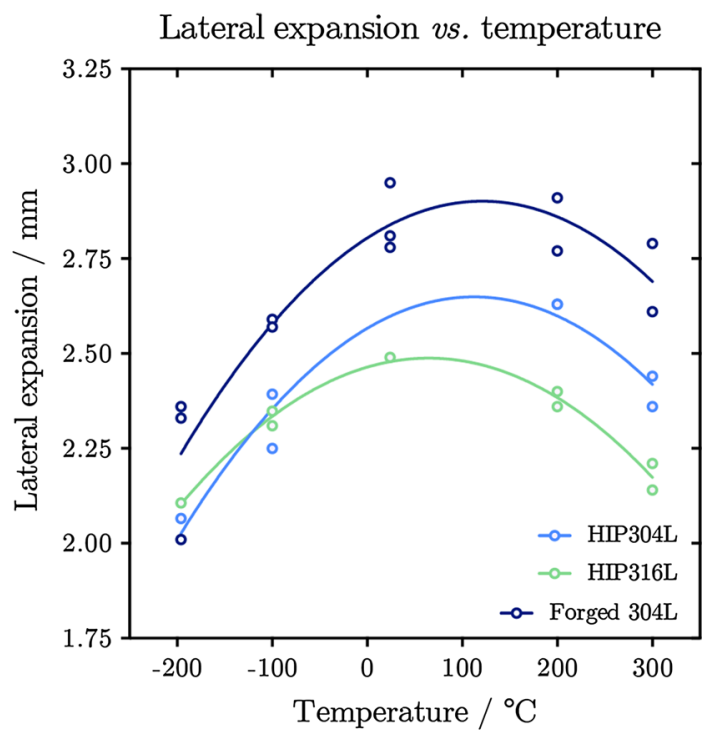

(b)

Fig. 8-Plots of $(a)$ measured lateral contraction vs. temperature, and $(b)$ lateral expansion vs. temperature.

\section{Martensite Detection Measurements}

Figure 10 shows EBSD maps taken on metallographic cross sections below the fracture surface of HIP316L Charpy specimens tested at (a) $77 \mathrm{~K}$ $\left(-196{ }^{\circ} \mathrm{C}\right)$, and (b) $293 \mathrm{~K}\left(20^{\circ} \mathrm{C}\right)$, showing the presence of both FCC and BCC crystal structures within $c a$. $1 \mathrm{~mm}^{2}$ of the fracture surface when specimens are failed at $77 \mathrm{~K}\left(-196^{\circ} \mathrm{C}\right)$, and a clear absence of detectable BCC structure over $c a .1 \mathrm{~mm}^{2}$ when specimens are failed at $293 \mathrm{~K}\left(20^{\circ} \mathrm{C}\right)$. Figures $10(\mathrm{c})$ and (d) show a similar view of a HIP304L tested specimen under the same conditions. Figures 10(e) and (f) show chemically equivalent F304L tested at $77 \mathrm{~K}$ and $293 \mathrm{~K}\left(-196^{\circ} \mathrm{C}\right.$ and $20^{\circ} \mathrm{C}$ ), respectively. 

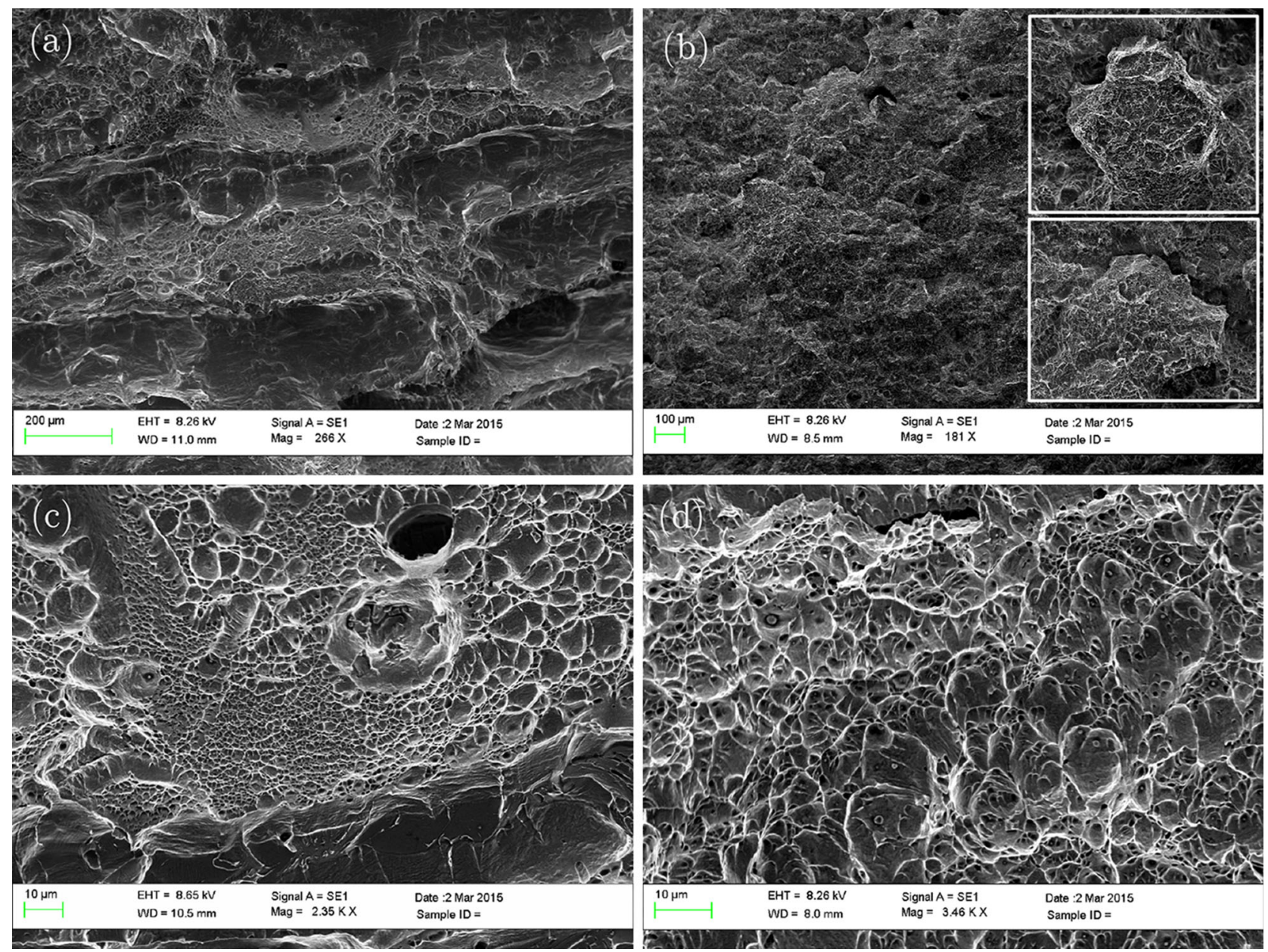

Fig. 9-SEM images of the Charpy-generated fracture surfaces of $(a, c) \mathrm{F} 304 \mathrm{~L}$, and $(b, d) \mathrm{HIP} 304 \mathrm{~L}$, tested at $77 \mathrm{~K}\left(-196{ }^{\circ} \mathrm{C}\right)$; showing subtly different fractographic features on the macro-scale, but extensive ductile dimpling on the micro-scale.

It is most likely that the BCC phase is strain-induced martensite, since its generation is temperature dependent and appears in regions close to the notch tip, where plasticity is most extreme. ${ }^{[15,18]}$ The phase fractions of austenite (FCC) and martensite (BCC), determined over the total scanned area $\left(c a .10 \mathrm{~mm}^{2}\right)$ from Figure 10, are tabulated in Table II. Since both the mounting resin and regions of excessive plasticity contribute to the total 'zero index count', the percentage of mounting resin was omitted from the phase fraction calculations, and the 'scaled phase fraction of BCC' was determined as a percentage of the sum of detectable FCC, detectable BCC, and total 'zero solutions' count. From Table II and the corresponding EBSD maps, it follows that 304L specimens failed at $77 \mathrm{~K}\left(-196{ }^{\circ} \mathrm{C}\right)$ generate $c a .25 \mathrm{pct}$ martensite, regardless of the material manufacture route. In general, the index count success rate for F304L was significantly smaller than HIP specimens. This is attributed to a much larger plastic deformation generated in the forged specimens, regardless of test temperature, which resulted in poor indexing through substantial matrix deformation. This observation is in agreement with the presented Charpy data/fracture surfaces, where forged specimens exhibited more ductility and plastic deformation than their HIP counterparts:
Figures 5, 6, 7, and 8(a), (b). Poorly indexed regions close to the notch root are also visible in HIP specimens tested at $293 \mathrm{~K}\left(20^{\circ} \mathrm{C}\right)$, and it is believed that this is due to the enhanced ductility of the HIP specimens at ambient temperatures.

The HIP316L specimens generated a significantly smaller BCC phase fraction ( $c a .15$ pct) than equivalent HIP304L specimens. In all cases where specimens were failed at $293 \mathrm{~K}\left(20^{\circ} \mathrm{C}\right)$, there was less than $1 \mathrm{pct}$ detectable BCC crystal structure. Failure at cryogenic temperatures has the effect of significantly increasing the degree of strain-induced martensite, and this transformation can be seen to initiate at the V-notch, the proportion of which decreases as distance from the notch increases.

In addition to EBSD mapping, microhardness mapping and ferromagnetic measurements were also performed on sectioned Charpy specimens tested at $77 \mathrm{~K}$ and $293 \mathrm{~K}\left(-196{ }^{\circ} \mathrm{C}\right.$ and $\left.20{ }^{\circ} \mathrm{C}\right)$. Figures $11(\mathrm{a})$ and (b) show microhardness maps of failed F304L Charpy specimens; tested at $77 \mathrm{~K}$ and $293 \mathrm{~K}\left(-196{ }^{\circ} \mathrm{C}\right.$ and $20{ }^{\circ} \mathrm{C}$ ), respectively. Figures 11 (c) and (d) microhardness maps of failed HIP304L Charpy specimens; tested at $77 \mathrm{~K}$ and $293 \mathrm{~K}\left(-196{ }^{\circ} \mathrm{C}\right.$ and $\left.20^{\circ} \mathrm{C}\right)$, respectively. Both specimens exhibit regions where hardness values 

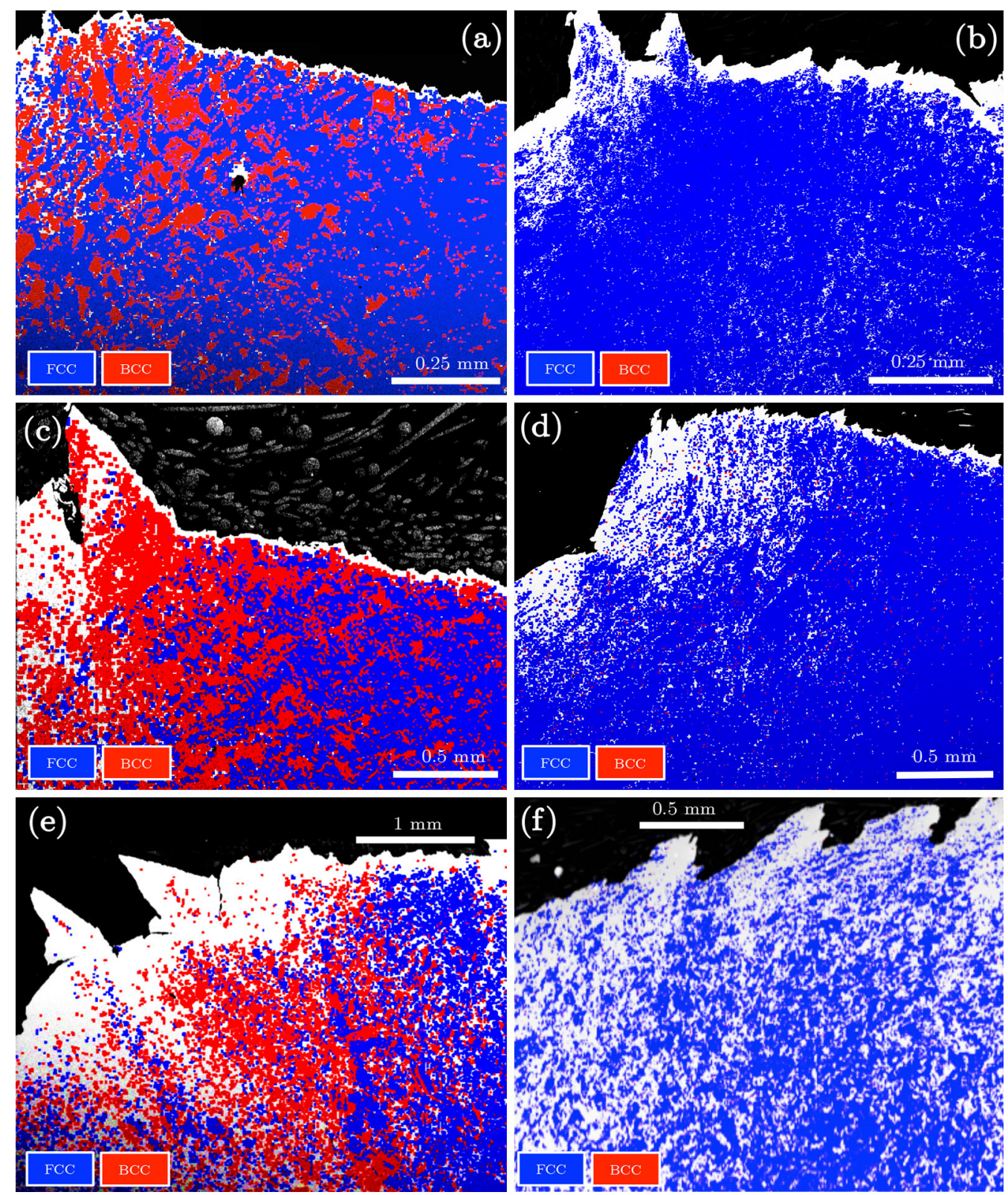

Fig. 10 - EBSD maps below the fracture surface of HIP 316L Charpy specimens tested at $(a) 77 \mathrm{~K}\left(-196{ }^{\circ} \mathrm{C}\right)$, and $(b) 293 \mathrm{~K}\left(20{ }^{\circ} \mathrm{C}\right)$, HIP304L Charpy specimens tested at $(c) 77 \mathrm{~K}\left(-196^{\circ} \mathrm{C}\right)$, and $(d) 293 \mathrm{~K}\left(20^{\circ} \mathrm{C}\right)$, and a comparative EBSD map of $\mathrm{F} 304 \mathrm{~L}$ tested at $(e) 77 \mathrm{~K}\left(-196{ }^{\circ} \mathrm{C}\right)$ and $(f) 293 \mathrm{~K}\left(20^{\circ} \mathrm{C}\right)$ is also presented.

Table II. FCC and BCC Phase Fractions Determined from EBSD

\begin{tabular}{lcccrr}
\hline Specimen & $\begin{array}{c}\text { FCC Phase } \\
\text { Fraction (Pct) }\end{array}$ & $\begin{array}{c}\text { BCC Phase } \\
\text { Fraction (Pct) }\end{array}$ & $\begin{array}{c}\text { Zero Solutions } \\
(\text { Pct) }\end{array}$ & $\begin{array}{c}\text { Resin } \\
\text { (Pct) }\end{array}$ & $\begin{array}{c}\text { Scaled } \\
\text { BCC Phase Fraction (Pct) }\end{array}$ \\
\hline (a) HIP316L 77 K $\left(-196^{\circ} \mathrm{C}\right)$ & 49 & 13 & 26 & 12 & 15 \\
(b) HIP316L 293 K $\left(20^{\circ} \mathrm{C}\right)$ & 46 & 0 & 40 & 14 & 0 \\
(c) HIP304L 77 K $\left(-196^{\circ} \mathrm{C}\right)$ & 20 & 18 & 32 & 30 & 26 \\
(d) HIP304L 293 K $\left(20^{\circ} \mathrm{C}\right)$ & 50 & 0 & 36 & 13 & 0 \\
(e) F304L 77 K $\left(-196^{\circ} \mathrm{C}\right)$ & 13 & 11 & 56 & 20 & 0 \\
(f) F304L 293 K $\left(20^{\circ} \mathrm{C}\right)$ & 20 & 0.06 & 68 & 12 & 0 \\
\hline
\end{tabular}

exceed $300 \mathrm{HV}$; within ca. $4 \mathrm{~mm}^{2}$ of the Charpy $\mathrm{V}$-notch, and in close proximity to the point of impact with the Charpy pendulum, though the regions of work hardening are clearly much more localized in the HIP specimen, which exhibits an appreciably smaller extent of plasticity than F304L. The degree of work hardening 

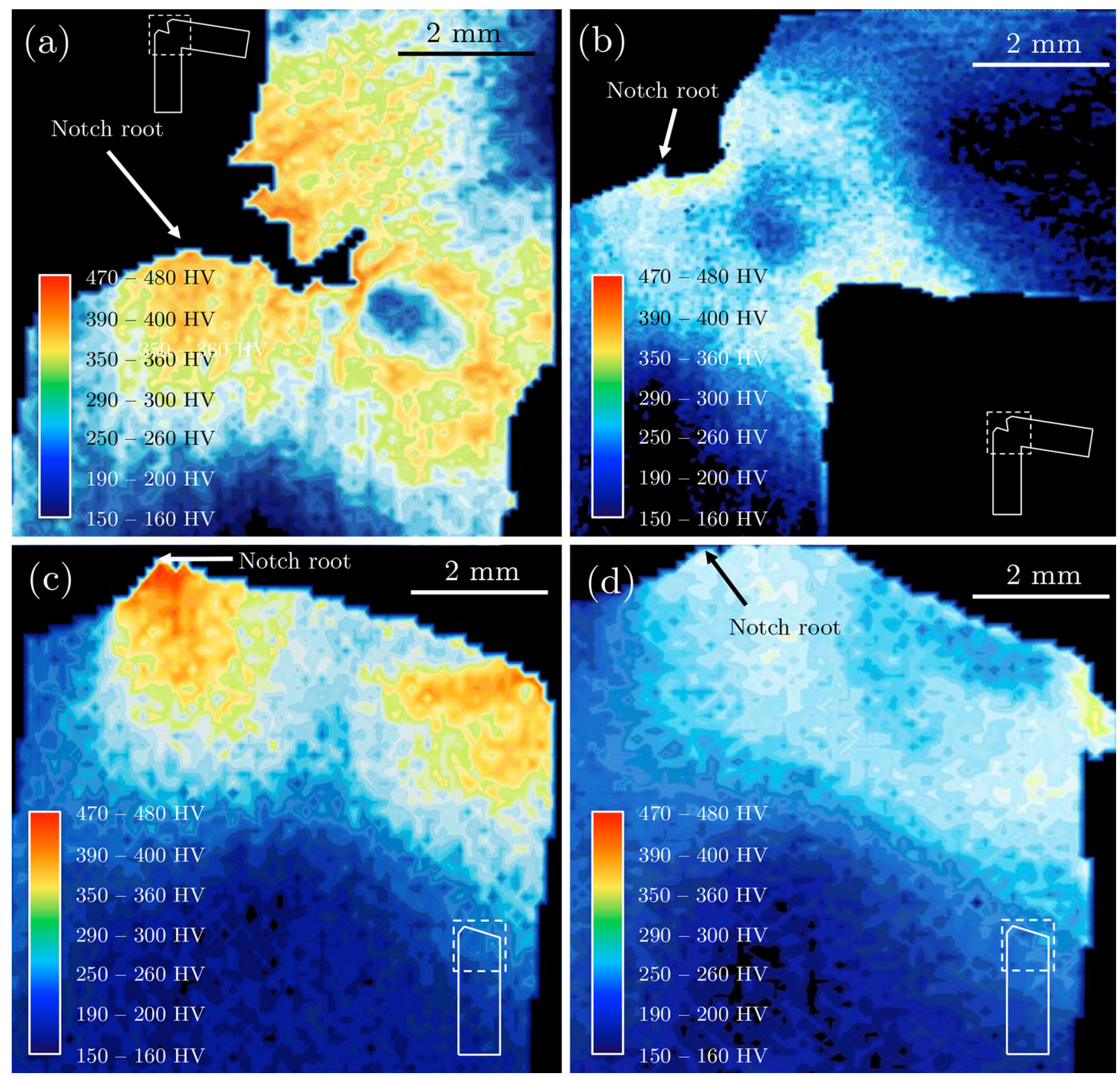

Fig. 11-Microhardness mapping below failed Charpy fracture surfaces, of $(a)$ F304L failed at $77 \mathrm{~K}\left(-196{ }^{\circ} \mathrm{C}\right)$, $(b)$ F304L failed at $293 \mathrm{~K}$ $\left(20{ }^{\circ} \mathrm{C}\right),(c) \mathrm{HIP} 304 \mathrm{~L}$, failed at $77 \mathrm{~K}\left(-196^{\circ} \mathrm{C}\right)$, and $(d) \mathrm{HIP} 304 \mathrm{~L}$, failed at $293 \mathrm{~K}\left(20^{\circ} \mathrm{C}\right)$. Schematics indicate the analysis region with respect to the sectioned Charpy specimen.

is evidently affected by decreasing temperature, and the differences in ductility between F304L (top) and HIP304L (bottom) are evident.

Ferritescope measurements taken in four different regions on sectioned Charpy specimens are tabulated in Figure 12. Christ and co-workers report ${ }^{[23]}$ using a Fischer ferritescope to determine martensite phase fractions, and obtained underestimated values to the actual martensite phase fractions present; they applied a correction factor of 1.58 to account for this. The table in Figure 12 therefore includes both the as-measured values (initial value) and corrected values (in parenthesis). No magnetic reading was detectable in remote locations from the fracture surface of any specimen and under any test conditions. In addition, no magnetic reading was obtained in any region on specimens failed at ambient temperature. In both F304L and HIP304L specimens, the largest ferromagnetic reading was observed in location (b), directly beneath the notch root, and the second largest readings measured in region (d): the reverse face where impact with the Charpy hammer occurs. The ferrite-scope data also highlight the increased degree of localization of the plastic zone in HIP304L $c f$. F304L, since HIP304L exhibits a slightly lower ferrite-scope reading in region (c).

The ferritescope data suggest a consistently smaller amount of martensite phase present in the HIP specimens. While a lower ferritescope reading was obtained 


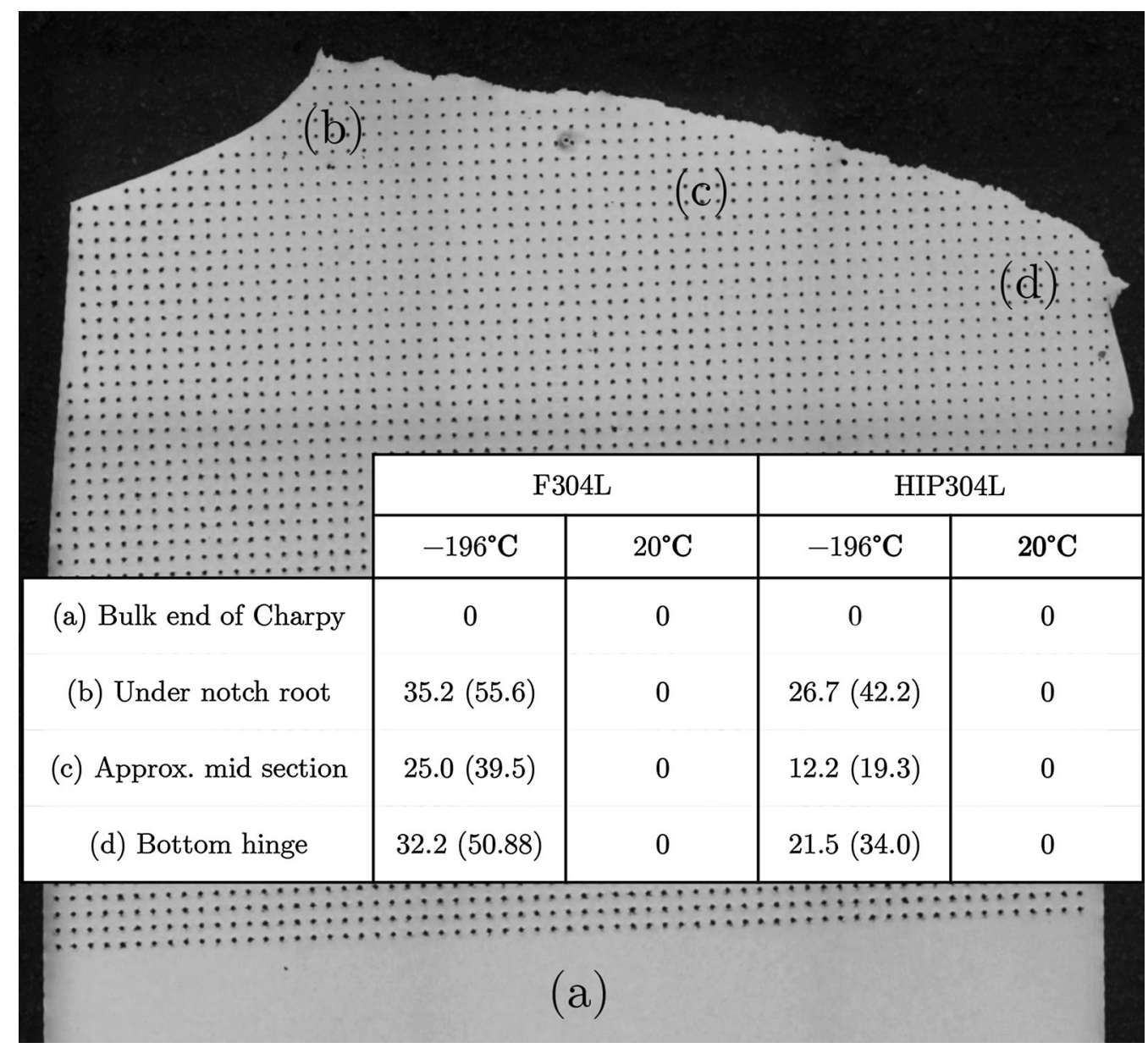

Fig. 12-Tabulated ferrite-scope data and accompanying image identifying the selected locations for measurement: first value is measured value using ferritescope, second value (in parenthesis) is converted value using conversion factor 1.58.

close to the notch root in the HIP304L specimen compared with the F304L specimen, a higher hardness was obtained in the HIP'd material in this region. The diameter of the ferritescope's active detector is on the order of mm, approximately an order of magnitude greater than the hardness indents. Nonetheless, the microhardness and magnetic data confirm the presence of martensite in tested HIP304L and F304L at $77 \mathrm{~K}$ $\left(-196{ }^{\circ} \mathrm{C}\right)$, on comparable scales, though the localization of this phase is much more centered around the notch and hinge in HIP304L and more diffuse beneath the whole fracture surface of F304L.

\section{DISCUSSIONS}

The oxygen content of the HIP materials is approximately one order of magnitude greater than chemically equivalent forged 304L (Table I). There are also visible micro-pores in the microstructure of the HIP'd materials. There is general agreement within the literature that high oxygen concentrations $(>100 \mathrm{ppm})$ in powder metallurgy materials and weld metals lead to a reduction in impact toughness, ${ }^{[24-28]}$ but in our work it is currently unclear whether the reduction in impact toughness is caused by oxygen involvement in the HIPping cycle or the presence of micro-porosity observed in the HIP'd materials. However we do show that the HIP'd materials' reduced Charpy impact toughness is accompanied by a greater oxygen content $c f$. forged material, and micro-porosity in the microstructure. We suspect that the two features are linked, and both contribute to the overall reduction in Charpy impact toughness. The 'micro-porosity' in the HIP materials could arise via two differing mechanisms; the first being a direct result of the HIPping process, whereby micro-porosity remains as a result of incomplete consolidation of the metal powder during HIPping. Since ductile failure occurs by the initiation, growth, and coalescence of ductile voids, the presence of a reasonable volume fraction of initial pores means that this first stage in the ductile failure mechanism is less significant than in equivalent forged materials, which does not exhibit micro-porosity, and the already-present micro-porosity is able to grow under the hydrostatic stresses and plastic strains generated during the Charpy impact. This may explain why the Charpy toughness is lower in micro-pore-containing HIP materials compared with forged material.

The second, more probable mechanism could be due to the presence of a substantial volume fraction of 
oxide-inclusions in the austenite matrix, which on their removal during metallographic sectioning and polishing, are left to reveal pores. ${ }^{[29]}$

Since we have shown evidence of oxide-inclusions in close proximity to the pores, as well as pores that appear to hold non-metallic material, this seems to be a more reasonable assessment. This hypothesis is accompanied by the fact the HIP material contains a substantially greater concentration of oxygen $c f$. forged 304L, in which this 'micro-porosity' was not observed, indicating that the 'pores' are related to the total oxygen content of the material. The presence of a substantial volume fraction of brittle, non-metallic inclusions would certainly have the effect of reducing the Charpy impact toughness and have an embrittlement effect on the HIP materials at depreciated temperatures.

The EBSD data, combined with the results of hardness and ferritescope measurements, indicate that strain-induced martensite is produced in regions close to the Charpy V-notch and fracture surfaces of both HIP 316L and HIP 304L Charpy specimens when tested at $77 \mathrm{~K}$ $\left(-196^{\circ} \mathrm{C}\right)$. The degree of martensite generated is negligible when specimens are tested at ambient temperatures or above. From the results presented, the degree of FCC to $\mathrm{BCC}$ phase transformation is on a comparable scale in both HIP and forged equivalents of 304L, whereas HIP316L shows approximately 10 pct less: Cryogenic fatigue testing of $316 \mathrm{~L}$ generally shows enhanced austenite stability over $304 \mathrm{~L}$, with respect to martensitic transformation, at depreciated temperatures. ${ }^{[30]}$

Microhardness testing and ferritescope detection gleaned similar datasets for HIP304L and F304L variations, which indicate that the degree of generated martensite close to the Charpy V-notch is of comparable magnitudes in specimens manufactured by HIPping and forging. It has been reported ${ }^{[31]}$ that although thermal stability, i.e., martensite formation on cooling, of austenite is heavily dependent on the austenite grain size, the mechanical stability and deformation-induced martensitic transformation of austenite is independent of grain size, which is consistent with the results presented herein since both HIP and forged variants of 304L undergo similar levels of martensitic transformation.

The greatest observed difference between HIP and forged materials, other than a consistently depreciated Charpy impact toughness, was with respect to the degree of plasticity generated within the failed specimens; forged Charpy specimens were seen to avoid complete failure regardless of test temperature (failed Charpy specimens remained in one piece, with a majority of un-fractured material remaining intact), whereas HIP Charpy specimens broke into two sections when tested at depreciated temperatures. It appears that there is an embrittlement and impact toughness temperature shift, of more than $100 \mathrm{~K}\left(100{ }^{\circ} \mathrm{C}\right)$, between the HIP and forged specimens.

This was also evident during EBSD mapping, in which a relatively small plastic zone was visible surrounding the notch of failed HIP specimens, preventing successful indexing in regions close to the notch root. This plasticity was seen to develop further into the matrix in chemically equivalent forged 304L material, making complete EBSD analysis less successful.

SEM analysis of the fracture surfaces revealed subtle differences in fracture morphology, where the F304L Charpy-generated fracture appeared relatively featureless except for substantial ductile dimpling, and the HIP specimens generated fracture surfaces exhibiting almost intergranular-like characteristics, whereby discontinuous grain-like geometries of ductile failure 'sections' were visible. This is likely to be attributed to the smaller grain size of the HIP304L. Significantly, no brittle-like fracture features were visible in any of the specimens, indicating that the fracture mechanism in both HIP and forged specimens occurs via complete ductile failure.

\section{CONCLUSIONS}

This paper has described the results and analysis of a series of Charpy tests undertaken on HIP'd and forged stainless steel specimens over the temperature range $77 \mathrm{~K}$ to $573 \mathrm{~K}\left(-196{ }^{\circ} \mathrm{C}\right.$ to $\left.+300{ }^{\circ} \mathrm{C}\right)$. The main conclusions of this work are as follows:

I. For 304L stainless steel, HIP'd specimens exhibit a lower Charpy energy that equivalent forged specimens at temperatures below ambient temperature, equivalent to an overall temperature shift of approximately $-100 \mathrm{~K}\left(-100^{\circ} \mathrm{C}\right)$.

II. HIP'd 316L stainless steel exhibits a Charpy energy vs temperature curve that is slightly below the HIP'd 304L material and equivalent to a temperature shift of $+50 \mathrm{~K}\left(+50{ }^{\circ} \mathrm{C}\right)$.

III. All materials exhibit a similar reduction in Charpy energy as a function of decreasing temperature, with gradients of $c a$. $0.5 \mathrm{~J}^{\circ} \mathrm{C}^{-1}$. This gradual decrease in Charpy toughness is attributed to an increasing proportion of stress-induced martensite with decreasing temperature.

IV. The Charpy impact toughness of all materials is similar at test temperatures between $473 \mathrm{~K}$ and $573 \mathrm{~K}\left(+200{ }^{\circ} \mathrm{C}\right.$ and $\left.+300{ }^{\circ} \mathrm{C}\right)$.

V. Fractographic analysis on both HIP and forged materials revealed similar fracture morphology: extensive ductile failure and no characteristic features of a brittle fracture mechanism.

VI. Similar phase fractions of stress-induced martensite transformation were detected close the Charpy notch in both HIP'd and forged variations of $304 \mathrm{~L}$ when tested at $77 \mathrm{~K}\left(-196^{\circ} \mathrm{C}\right)$, indicating that martensite transformation is not the key reason for the difference in Charpy toughness. No martensite was detectable in any materials when tested at ambient temperature.

VII. Micron-scale porosity was present in both HIP materials, and was not observable in the forged material. This micro-porosity is accompanied by a larger oxygen content in the HIP'd materials. We suspect this micro-porosity contributes to the depreciated Charpy toughness of the HIP materials through the formation of a significant volume fraction of oxide-inclusions through the 
involvement of high oxygen concentrations resulting in the HIPped material.

\section{ACKNOWLEDGMENTS}

We thank the UK EPSRC for funding of this research project. Thanks also goes to Mr. Adam Bannister and Mr. Stuart Sotheran at Tata Steel for their support in the measurement of all Charpy data, as well as Areva for the provision of all materials. We also appreciate the help of Mr. Colin Burnfield and Mr. Vince McKee at BAE Systems for performing chemical analysis of materials.

\section{REFERENCES}

1. H.V. Atkinson and S. Davies: Metall. Mater. Trans. A, 2000, vol. 31A, pp. 2981-3000.

2. Charles. Barre: Adv. Mater. Process., 1999, vol. 155, pp. 47-48.

3. N.A. Fleck and R.A. Smith: Powder Metall., 1981, vol. 24, pp. $121-25$.

4. G.A. Rao and M. Kumar: Mater. Sci. Technol., 1997, vol. 13, pp. $1027-31$.

5. J.J. Eckenrod and K.E. Pinnow: Advances in Powder Metallurgy and Particulate Materials, (1993), pp. 131-40.

6. H.T. Larker and R. Lundberg: J. Eur. Ceram. Soc., 1999, vol. 19, pp. 2367-73.

7. Y.C. Jeon and K.T. Kim: Int. J. Mech. Sci., 1999, vol. 41, pp. $815-30$.

8. G.A. Rao, D.V.V. Satyanarayana, M. Srinivas, and D.S. Sarma: Powder Metall., 2009, vol. 52, pp. 244-49.

9. V. Viswanathan, T. Laha, K. Balani, A. Agarwal, and S. Seal: Mater. Sci. Eng. R, 2006, vol. 54, pp. 121-85.

10. J.K.L. Lai, K.H. Lo and C.H. Shek: Stainless Steel An Introduction and their Recent Developments, 2012.

11. P.J. Jacques, J. Ladrière, and F. Delannay: Metall. Mater. Trans. A, 2001, vol. 32A, pp. 2759-68.
12. H.F. López and A.J. Saldivar-Garcia: Metall. Mater. Trans. A, 2008, vol. 39A, pp. 8-18.

13. Z. Nishiyama: Martensitic Transformation, Elsevier, Amsterdam, 2012.

14. S.M.C. van Bohemen and J. Sietsma: Metall. Mater. Trans. A, 2009, vol. 40A, pp. 1059-68.

15. S.S. Hecker, M.G. Stout, K.P. Staudhammer, and J.L. Smith: MTA, 1982, vol. 13, pp. 619-26.

16. B.T. Skoczeń: Compensation Systems for Low Temperature Applications, Springer, Berlin, 2004, pp. 119-36.

17. S. Takahashi, J. Echigoya, T. Ueda, X. Li, and H. Hatafuku: $J$. Mater. Process. Technol., 2001, vol. 108, pp. 213-16.

18. K.P. Staudhammer, L.E. Murr, and S.S. Hecker: Acta Metall., 1983, vol. 31, pp. 267-74.

19. Ercan. Cakmak, Sven.C. Vogel, and Hahn. Choo: Mater. Sci. Eng. $A$, 2014, vol. 589, pp. 235-41.

20. ASTM A370-14: Standard Test Methods and Definitions for Mechanical Testing of Steel Products, ASTM International, West Conshohocken, 2014.

21. ASTM E3-01: Standard Practice for Preparation of Metallographic Specimens. ASTM International, West Conshohocken, 2001.

22. ASTM E112-96: Standard Test Methods for Determining Average Grain Size. ASTM International, West Conshohocken, 1996.

23. H.-J. Christ, U. Krupp, C. Mueller-Bollenhagen, I. Roth and M. Zimmermann: Proceedings of the 12th International Conference on Fracture, Ottawa, Canada, 2009.

24. J. Liao, M. Hotta, and A. Koshi: Mater. Lett., 2011, vol. 65, pp. 2995-99.

25. Y. Sato, T. Maie and T. Kuwana: Proceedings of the International Conference on Offshore Mechanics and Arctic Engineering-OMAE, 1995, pp. 485-90.

26. O. Kamiya, H. Fujita, T. Enjo, and Y. Kikuchi: Q. J. Jpn. Weld. Soc., 1985, vol. 3, pp. 574-81.

27. Z. Oksiuta, E. Boehm-Courjault, and N. Baluc: J. Mater. Sci., 2010, vol. 45, pp. 3921-30.

28. A. Lind, J. Sundström, and A. Peacock: Fusion Eng. Des., 2005, vols. 75-79, pp. 979-83.

29. M. Godec: Mater. Tehnol., 2011, vol. 45, pp. 85-90.

30. J. Man, K. Obrtlík, M. Petrenec, P. Beran, M. Smaga, A. Weidner, J. Dluhoš, T. Kruml, H. Biermann, D. Eifler, and J. Polák: Proc. Eng., 2011, vol. 10, pp. 1279-84.

31. Y. Matsuoka, T. Iwasaki, N. Nakada, T. Tsuchiyama, and S. Takaki: ISIJ Int., 2013, vol. 53, pp. 1224-30. 